\title{
IMPORTANCE OF FASTING INSULIN LEVELS IN INSULIN RESISTANCE AND DIABETES MELLITUS (HOMEOSTATIC MODEL ASSESSMENT)
}

\author{
Irfan Ahamed H. B', Aniruddha Udupa $K^{2}$, Mohammed Ismail ${ }^{3}$, Syed Aman Jagirdar', Naveen Sagar H. M⿻ \\ ${ }^{1}$ Assistant Professor, Department of Medicine, Al-Ameen Medical College, Bijapur. \\ ${ }^{2}$ Assistant Professor, Department of Pulmonology, Subbaiah Medical College, Shimoga. \\ 3Postgraduate, Department of Medicine, Al-Ameen Medical College, Bijapur. \\ 4 Postgraduate, Department of Medicine, Al-Ameen Medical College, Bijapur. \\ 5 Postgraduate, Department of Medicine, Al-Ameen Medical College, Bijapur.
}

\begin{abstract}
BACKGROUND

Insulin resistance is the subnormal biological response to normal insulin concentrations. In Indian population, there is a rapid escalating epidemic of insulin resistance syndrome. Insulin resistance is a central feature of impaired glucose tolerance, type- 2 diabetes, hypertension, dyslipidaemia, atherosclerosis, endothelial dysfunction and coronary artery disease.
\end{abstract}

Aim of the Study:

1. To find the co-relation between fasting insulin levels and diabetes.

2. To determine the incidence and prevalence of insulin resistance in young individuals.

\section{MATERIALS AND METHODS}

100 young individuals (50 diabetic and 50 non-diabetic) having Insulin resistance with age $<40$ years are included in the said study. Homeostatic model assessment (HOMA) is the standard method used in this study to identify the subjects having insulin resistance and the HOMA value obtained above 3.5 is considered significant to define insulin resistance.

\section{RESULTS}

1. Insulin resistance is predominant in males versus females with mean age of $32 \pm 4.92$ in Diabetic group and $25.80 \pm 7.21$ in the NonDiabetic group. 2. Insulin resistance is strongly associated with diabetes, hypertension, obesity, hyperlipidaemia, hyperuricaemia and it is showing a significant P value. 3. High values of HOMA are seen in prediabetic and non-diabetic young individuals.

\section{CONCLUSION}

High incidence and prevalence of insulin resistance is seen in non-diabetic young individuals with hypertension, obesity, hyperlipidaemia and hyperuricaemia. Insulin resistance in prediabetic young individuals is to be treated with lifestyle modification and medication. HOMA is a standard measure to define insulin resistance.

\section{KEYWORDS}

Fasting Insulin Levels, Insulin Resistance, HOMA, Comorbidities, and Prediabetes.

HOW TO CITE THIS ARTICLE: Ahamed IHB, Udupa AK, Ismail M et al. Importance of fasting insulin levels in insulin resistance and diabetes mellitus (homeostatic model assessment). J. Evolution Med. Dent. Sci. 2016;5(90):6685-6688, D0I: $10.14260 /$ jemds/2016/1512

\section{BACKGROUND}

Prevalence rates of insulin resistance syndrome reported for white populations ranged from $3-16 \%$; a rate of less than $2 \%$ was reported among Japanese populations.[1,2]

Type A insulin resistance typically occurs in younger patients, while type B insulin resistance occurs more often in older women. Women with polycystic ovary syndrome (PCOS) usually present in their mid-20s. Many rare disorders of insulin resistance present in early life (e.g., leprechaunism [First year of life], lipodystrophic states [Ages 6-9 years until early puberty]).

Financial or Other, Competing Interest: None.

Submission 20-10-2016, Peer Review 02-11-2016,

Acceptance 03-11-2016, Published 09-11-2016.

Corresponding Author:

Dr. Irfan Ahamed H. B,

S/O K B Basheer Ahamed, $1^{\text {st }}$ Stage, $2^{\text {nd }}$ Cross,

Door \#15, Iqbal Manzil,

Dr. Ram Manohar Lohiya Nagar,

Shimoga-577201, Karnataka.

E-mail:dr.irfan28@gmail.com

DOI: $10.14260 /$ jemds/2016/1512
The strongest relationship between insulin resistance and cardiovascular risk factors is observed in middle-aged persons rather than in older individuals, although cardiovascular morbidity and mortality increase with age. Very less studies have been done in young people aged less than 40 years.

Despite the growing obesity epidemic and insulin resistance in children, no clear diagnostic criteria and surrogate markers have been identified. An international consensus group recommended against screening children for insulin resistance in children based on existing methodology and criteria.[3]

Insulin resistance syndrome is found in all races. The degree of clustering of the risk variables of the metabolic syndrome is generally considered to be higher among whites. However, prevalence rates of the various components of the metabolic syndrome tend to be higher among non-white populations.[4]

Acanthosis nigricans, a common physical sign of insulin resistance syndrome, occurs in all ethnic groups, but the prevalence is higher in Hispanics and blacks than it is in whites. 
There is a rapidly escalating epidemic of insulin resistance syndrome (Diabetes and coronary heart disease) in India. Contribution of genes and environment is under debate. Small size at birth coupled with subsequent obesity increases risk for insulin resistance syndrome in later life. The tendency of Indians to have higher body fat and central adiposity compared with other races may be programmed in utero.

The adipose tissue releases not only fatty acids but also a number of pro-inflammatory cytokines, which increase insulin resistance and cause endothelial dysfunction. Crowding, infections, and environmental pollution in Indian cities may increase cardiovascular risk by stimulating fat cells. Prevention of diabetes and coronary heart disease in India will have to be approached throughout the life cycle.[5]

Hence, it is important to evaluate the young high risk individuals for insulin resistance and to study its significant comorbidities.

\section{Objectives of Study}

- To find the correlation between fasting insulin levels and diabetes.

- $\quad$ To determine the incidence and prevalence of insulin resistance in young individuals.

- To study insulin resistance and its comorbidities in young individuals.

- To study insulin resistance in non-diabetic young individuals.

- To study insulin resistance and its comorbidities in prediabetic individuals.

\section{MATERIALS AND METHODS}

\section{Source of Data}

100 patients (50 non-diabetic patients with eligibility criteria and 50 with type 2 diabetes mellitus) attending Diabetic OPD in Al-Ameen Medical College Hospital and Govt. District Hospital Bijapur affiliated to Al-Ameen Medical College Hospital of age group less than or equal to 40 years old during a duration of Dec. 2012 - Oct. 2014.

\section{Period of Study}

Dec. 2012-Oct. 2014.

\section{Design of Study}

Prospective Study.

\section{Eligibility Criteria}

1. Patients with high risk group.

2. Patients with family history of diabetes mellitus and Hypertension, Obesity, Hyperlipidaemia, Gestational diabetes and PCOD (Polycystic ovarian disease).

3. Age less than or equal to 40 .

\section{Exclusion Criteria}

1. Age more than 40 .

2. Hypothyroidism and Cushing's syndrome.

3. Non-obese type 2 diabetes.

\section{Preliminary Measures}

1. Fasting Glucose Levels.

2. Lipid Profile.

3. Fasting Insulin Levels.

4. HbA1C.
5. Waist-Hip Ratio.

6. Serum Uric Acid.

Subjects fulfilling to the inclusion criteria and preliminary tests for insulin resistance are further evaluated with HOMA (Homeostasis model assessment). This is a prospective study following a trial for 2 years.

\section{RESULTS}

In our study, we observed that $11(22 \%)$ of the patients in Diabetic group and 34 (68\%) in Non-Diabetic group were having raised insulin levels.

In our study, we observed that 27 (54\%) of the patients in Diabetic group and 35 (70\%) in Non-Diabetic group were having raised HOMA values.

In our study, we observed that the mean FBS levels in Diabetic group of patients is $140.18 \pm 52.31$ and $94 \pm 42 \mathrm{mg} / \mathrm{dL}$ in Non-Diabetic group with $P$ value of $<0.001^{* *}$.

In our study, we observed that the mean HbA1C levels in Diabetic group of patients is $7.54 \pm 1.18$ and $5.85 \pm 0.47$ in NonDiabetic group with $\mathrm{P}$ value of $<0.001^{* *}$.

In our study, we observed that the mean HOMA values in Diabetic group of patients is $5.04 \pm 5.08$ and $9.22 \pm 12.55$ in NonDiabetic group with $\mathrm{P}$ value of 0.031 .

In our study, we observed that the mean Uric Acid levels in Diabetic group of patients is $5.91 \pm 1.85$ and $7.39 \pm 2.45$ in NonDiabetic group with P value of 0.003 .

In our study, we observed that out of 27 positive HOMA patients in Diabetic group, 15 (55.56\%) patients were having raised BMI levels and in 35 positive HOMA patients in NonDiabetic group, 25 (71.4\%) patients were having raised BMI levels. It is seen here that Non-Diabetic high risk group patients are having strong association with obesity and Insulin Resistance.

In our study, we observed that out of 27 positive HOMA patients in Diabetic group, 18 (66.67\%) patients were having raised WHR and in 35 positive HOMA patients in Non-Diabetic group, $29(82.86 \%)$ patients were having raised WHR. It is seen here that Non-Diabetic high risk group patients are having strong association with obesity and Insulin Resistance.

In our study, we observed that out of 27 positive HOMA patients in Diabetic group, 19 (70.38\%) patients were having raised FBS levels and in 35 positive HOMA patients in NonDiabetic group, $10(28.6 \%)$ patients were having raised FBS levels. It is seen here that Diabetic group patients are having strong association with Type 2 Diabetes Mellitus and Insulin Resistance.

In our study, we observed that out of 27 positive HOMA patients in Diabetic group, 24 (88.88\%) patients were having raised HbA1c levels and in 35 positive HOMA patients in NonDiabetic group, $0(0 \%)$ patients were having raised $\mathrm{HbA} 1 \mathrm{C}$ levels. It is seen here that Diabetic group patients are having strong association with Type 2 Diabetes Mellitus and Insulin Resistance.

In our study, we observed that out of 27 positive HOMA patients in Diabetic group, $9(33.5 \%)$ patients were having hypertension and in 35 positive HOMA patients in NonDiabetic group, 26 (74.29\%) patients were having hypertension. It is seen here that Non-Diabetic group patients are having strong association with Hypertension and Insulin Resistance. 


\begin{tabular}{|c|c|c|c|c|}
\hline \multirow{2}{*}{ Insulin } & \multicolumn{2}{|c|}{ Diabetic Group } & \multicolumn{2}{c|}{ Non-Diabetic Group } \\
\cline { 2 - 5 } & No & \% & No & $\%$ \\
\hline Raised & 11 & 22.0 & 34 & 68.0 \\
\hline Normal & 39 & 78.0 & 16 & 32.0 \\
\hline Total & 50 & 100.0 & 50 & 100.0 \\
\hline \multicolumn{4}{|c|}{ Table 1. Insulin levels in Two } \\
Groups of Patients Studied \\
\hline
\end{tabular}

$\mathrm{P}<0.001^{* *}$, Significant, Chi-Square test.

In our study, we observed that $11(22 \%)$ of the patients in Diabetic group and $34(68 \%)$ in Non-Diabetic group were having raised Insulin levels.

\begin{tabular}{|c|c|c|c|c|}
\hline \multirow{2}{*}{ HOMA } & \multicolumn{2}{|c|}{$\begin{array}{c}\text { Diabetic } \\
\text { Group }\end{array}$} & \multicolumn{2}{c|}{$\begin{array}{c}\text { Non-Diabetic } \\
\text { Group }\end{array}$} \\
\cline { 2 - 5 } & No & $\mathbf{\%}$ & No & $\%$ \\
\hline Raised & 27 & 54.0 & 35 & 70.0 \\
\hline Normal & 23 & 46.0 & 15 & 30.0 \\
\hline Total & $\mathbf{5 0}$ & $\mathbf{1 0 0 . 0}$ & $\mathbf{5 0}$ & $\mathbf{1 0 0 . 0}$ \\
\hline \multicolumn{3}{c}{$\begin{array}{c}\text { Table 2. HOMA Values in Two } \\
\text { groups of Patients Studied }\end{array}$} \\
\hline
\end{tabular}

$\mathrm{P}=0.099+$, Significant, Chi-Square test.

In our study, we observed that 27 (54\%) of the patients in Diabetic group and 35 (70\%) in Non-Diabetic group were having raised HOMA values.

\begin{tabular}{|c|c|c|c|}
\hline & $\begin{array}{c}\text { Diabetic } \\
\text { Group }\end{array}$ & $\begin{array}{c}\text { Non-Diabetic } \\
\text { Group }\end{array}$ & $\begin{array}{c}\text { P } \\
\text { Value }\end{array}$ \\
\hline FBS & $140.18 \pm 52.31$ & $94.42 \pm 13.07$ & $<0.001^{* *}$ \\
\hline HbA1c & $7.54 \pm 1.18$ & $5.85 \pm 0.47$ & $<0.001^{* *}$ \\
\hline Insulin & $14.33 \pm 10.40$ & $41.68 \pm 65.73$ & $0.005^{* *}$ \\
\hline HOMA & $5.04 \pm 5.08$ & $9.22 \pm 12.55$ & $0.031^{*}$ \\
\hline Uric acid & $5.91 \pm 1.85$ & $7.39 \pm 2.95$ & $0.003^{* *}$ \\
\hline \multicolumn{4}{|c|}{ Table 3. Comparison of FBS, HBA1C, } \\
Insulin in Two Groups of Patients Studied \\
\hline \multicolumn{4}{|c}{}
\end{tabular}

\begin{tabular}{|c|c|c|c|c|}
\hline & \multicolumn{2}{|c|}{ Diabetic Group } & \multicolumn{2}{c|}{$\begin{array}{c}\text { Non-Diabetic } \\
\text { Group }\end{array}$} \\
\cline { 2 - 5 } & r value & P value & r value & P value \\
\hline $\begin{array}{c}\text { HOMA vs. BMI } \\
\text { (kg/m²) }\end{array}$ & 0.160 & 0.914 & 0.350 & 0.013 \\
\hline $\begin{array}{c}\text { HOMA vs. waist-hip } \\
\text { ratio }\end{array}$ & 0.262 & 0.671 & 0.612 & 0.017 \\
\hline HOMA vs. FBS & 0.536 & $<0.001^{* *}$ & 0.125 & 0.387 \\
\hline $\begin{array}{c}\text { HOMA vs. Total } \\
\text { cholesterol }\end{array}$ & 0.570 & 0.066 & 0.430 & 0.067 \\
\hline HOMA vs. TGL & 0.554 & 0.012 & 0.435 & 0.027 \\
\hline HOMA vs. LDL & 0.016 & 0.911 & 0.139 & 0.034 \\
\hline HOMA vs. HDL & 0.309 & $0.029^{*}$ & 0.197 & 0.502 \\
\hline HOMA vs. HbA1c & 0.384 & $0.006^{* *}$ & 0.105 & 0.468 \\
\hline HOMA vs. HTN & 0.623 & $0.003^{* *}$ & 0.581 & $<0.001^{* *}$ \\
\hline HOMA vs. Uric Acid & 0.411 & 0.041 & 0.311 & 0.061 \\
\hline $\begin{array}{c}\text { HOMA vs. Insulin } \\
\text { levels }\end{array}$ & 0.211 & 0.092 & 0.413 & 0.071 \\
\hline Table 4. Pearson Correlation of HOMA with Study \\
Variables & \multicolumn{2}{|l}{} \\
\hline
\end{tabular}

\section{DISCUSSION}

Insulin Resistance and Type 2 Diabetes Mellitus (FBS, HbA1C, Fasting Insulin Levels):

In our study, we observed that correlation of FBS with HOMA in Diabetic group of patients is $r=0.536$ which is showing large correlation with $\mathrm{P}<0.001^{* *}$ which is strongly significant. In Non-Diabetic group of patients, $r=0.125$ which is showing small correlation with $\mathrm{P}=0.387$ which is not significant.

In our study, we observed that correlation of HbA1C with HOMA in Diabetic group of patients is $r=0.384$ which is showing small correlation with $\mathrm{P}=0.006^{*}$ which is moderately significant. In Non-Diabetic group of patients, $r=0.105$ which is showing small correlation with $\mathrm{P}=0.468$ which is not significant.

In our study, we observed that Insulin Resistance has strong association with HOMA in Diabetics.

McKeigue et al[6] hypothesised that insulin resistance may be common in these people and that this may be the underlying mechanism leading to the predisposition to diabetes mellitus.

Reaven et al[7] postulated that where there is resistance to insulin stimulated glucose uptake, deterioration of glucose tolerance can only be prevented if the beta cells are able to maintain increased insulin secretion. If this state of hyperinsulinaemia cannot be maintained, then loss of glucose tolerance would result, followed by overt diabetes mellitus. Thus, a state of hyperinsulinaemia resulting from insulin resistance would be characteristic of individuals or groups at increased risk of diabetes.

In our study, we observed that the mean Insulin levels in Diabetic group of patients is $14.33 \pm 10.40$ and $41.68 \pm 65.73$ in Non-Diabetic group of with P value of $0.005^{* *}$.

\section{Insulin Resistance and Prediabetes}

Insulin resistance increases the risk of developing type 2 diabetes and prediabetes. Prediabetes usually occurs in people who already have insulin resistance. Although insulin resistance alone does not cause type 2 diabetes, it often sets the stage for the disease by placing a high demand on the insulin-producing beta cells. In prediabetes, the beta cells can no longer produce enough insulin to overcome insulin resistance, causing blood glucose levels to rise above the normal range.

Once a person has prediabetes, continued loss of beta cell function usually leads to type 2 diabetes. People with type 2 diabetes have high blood glucose. Over time, high blood glucose damages nerves and blood vessels, leading to complications such as heart disease, stroke, blindness, kidney failure, and lower-limb amputations.

Studies have shown that most people with prediabetes develop type 2 diabetes within 10 years, unless they change their lifestyle. Lifestyle changes include losing 5 to 7 percent of their body weight-10 to 14 pounds for people who weigh 200 pounds by making changes in their diet and level of physical activity.

Hence, it becomes important for all of us to treat and try to reduce the prevalence of Insulin Resistance among our young and prediabetic individuals by following methods. 


\section{Lifestyle Modification}

Insulin resistance can be managed in two ways. First, the need for insulin can be reduced. Second, the sensitivity of cells to the action of insulin can be increased.

The need for insulin can be reduced by altering the diet, particularly the carbohydrates in the diet. Carbohydrates are absorbed into the body as they are broken up into their component sugars. Some carbohydrates break and absorb faster than others; these are referred to having a high glycaemic index. These carbohydrates increase the blood glucose level more rapidly and require the secretion of more insulin to control the level of glucose in the blood.

Several studies have confirmed that weight loss and even aerobic exercise without weight loss increase the rate at which glucose is taken from the blood by muscle cells as a result of improved sensitivity.

\section{Medications}

Metformin is a medication that is used for treating type 2 diabetes. It exerts two actions that help to control blood glucose levels. Metformin prevents the liver from releasing glucose into the blood, and it increases the sensitivity of muscle and fat cells to insulin. So, the muscle and fat remove more glucose from the blood. By these actions, metformin lowers blood insulin levels.

The STOP NIDDM (Study to Prevent Non-insulin Dependent Diabetes Mellitus) trial assessed individuals with insulin resistance by treating with acarbose. Acarbose slows the gut's absorption of sugars, which reduces the demand for insulin after a meal. This study suggested that acarbose could reduce the development of type 2 diabetes by $25 \%$.

Thiazolidinediones comprise another class of drugs which increase sensitivity to insulin, including pioglitazone and rosiglitazone. These medications are no longer used routinely, in part because of liver toxicity that requires monitoring of liver blood tests.

\section{CONCLUSION}

- High incidence and prevalence of Insulin Resistance is seen in young individuals.
- Insulin Resistance is having strong association with comorbidities like hypertension, obesity, hyperlipidaemia, hyperuricaemia.

- High incidence and prevalence of Insulin Resistance in Non-Diabetic individuals who are in high risk group.

- Insulin Resistance in young individuals and prediabetics has to be treated with lifestyle modification and medication to avoid complications and comorbidities.

- HOMA is a standard measure for Insulin Resistance.

\section{REFERENCES}

1. Moadab MH, Kelishadi R, Hashemipour M, et al. The prevalence of impaired fasting glucose and type 2 diabetes in a population-based sample of overweight/obese children in the Middle East. Pediatr Diabetes 2010;11(2):101-6.

2. Sarti C, Gallagher J. The metabolic syndrome: prevalence, CHD risk, and treatment. J Diabetes Complications 2006;20(2):121-32.

3. Levy-Marchal C, Arslanian S, Cutfield W, et al. Insulin resistance in children: consensus, perspective, and future directions. J Clin Endocrinol Metab 2010;95(12):5189-98.

4. Beck-Nielsen H. General characteristics of the insulin resistance syndrome: prevalence and heritability. European group for the study of insulin resistance (EGIR). Drugs 1999;58(Suppl 1):7-10.

5. Yajnik CS. The insulin resistance epidemic in India: fetal origins, later lifestyle, or both? International Life Sciences Institute 2009. Article first published online: 27 APR DOI: 10.1111/j.1753-4887. 2001.tb01898.x@ 2001.

6. McKeigue PM, Miller GJ, Marmot MG. Coronary heart disease in south Asians overseas: a review. J Clin Epidemiol 1989;42(7):597-609.

7. Reaven GM. Role of insulin resistance in human disease. Diabetes 1988;37(12):1595-607. 